\title{
"POLÍTICAS PÚBLICAS PARA A EDUCAÇ̃̃o ESCOLAR INDÍGENA E OS DESAFIOS MUNICIPAIS DA CIDADE DE DOURADOS/MS
}

\author{
Public policies for indigenous school education and municipal challenges in the city \\ of Dourados/MS
}

\section{Políticas públicas para la educación escolar indígena y desafíos municipales en la ciudad de Dourados/MS}

Ilma Saramago*

Marilda Moraes Garcia Bruno**

\begin{abstract}
[...] alguns indígenas ainda ficam na ideia de que a escola (indígena) é a secretaria de educação. [...] É necessário que a escola seja levada para a comunidade. Não dá para deixar a escola somente em quatro paredes, não são somente os alunos que fazem parte da escola, toda comunidade faz parte da escola, por isso a escola tem que ser aberta. A escola é a comunidade e a comunidade é a escolal.
\end{abstract}

\begin{abstract}
Resumo
As políticas públicas educacionais voltadas para os povos indígenas têm revelado significativos avanços desde a Constituição Federal Brasileira de 1988, a qual dispõe de Artigos específicos que garantem à educação escolar indígena o respeito a língua materna e ao modo próprio de aprender das comunidades. Nessa perspectiva, este artigo busca discutir as políticas públicas implementadas e voltadas para a educação escolar indígena tanto ao que tange o nível nacional, como o nível estadual e municipal, em especial no município de Dourados/MS, local onde encontra-se a segunda maior população indígena. Trata-se de um recorte da nossa Tese de Doutoramento, defendida no ano 2019 pelo Programa de Pós-Graduação em Educação da Universidade Federal da Grande Dourados, cuja metodologia pautou-se nos estudos Culturais e na etnografia educacional. $\mathrm{O}$ estudo aponta que mesmo com os avanços acerca das políticas públicas nacionais ainda há um grande desafio no campo municipal, pois suas políticas não contemplam as necessidades e especificidades da educação escolar dos indígenas de Dourados/MS. Esperamos que tal discussão contribua para que as políticas públicas locais
\end{abstract}

\footnotetext{
* Doutora em Educação pela Universidade Federal da Grande Dourados. Atuou como Professora contratada no curso de Pedagogia da Universidade Federal da Grande Dourados. Universidade Federal de Mato Grosso do Sul e Universidade Estadual de Mato Grosso do Sul. Pesquisadora do Grupo de Estudos e Pesquisa em Educação Inclusiva (GEPEI). E-mail: ilmasaramago@hotmail.com Orcid: https://orcid.org/0000-0002-5430-111.

** Doutora em Educação pela Universidade Estadual Paulista - Júlio de Mesquita Filho. Professora Associada do Programa de Pós-Graduação em Educação da Universidade Federal da Grande Dourados. Pesquisadora do Grupo de Estudos e Pesquisa em Educação Inclusiva (GEPEI). E-mail: mgbruno@uol.com.br Orcid: https://orcid.org/0000-0002-1568-2185.

${ }^{1}$ Relato de uma aluna Indígena Guarani durante a aula no curso de Especialização em Educação Intercultural, oferecido pela Faculdade Intercultural Indígena - Universidade Federal da Grande Dourados (2014-2015)
} 
sejam repensadas a fim de cumprir e ampliar as garantias legais já conquistadas nacionalmente pelos indígenas.

PALAVRAS-CHAVE: Políticas Públicas. Dispositivos legais. Educação Escolar Indígena.

\begin{abstract}
Public educational policies aimed at the indigenous peoples have revealed significant advances since the 1988 Brazilian Federal Constitution, which has specific Articles that guarantee indigenous school education respect for the mother tongue and the communities' own way of learning. In this perspective, this article seeks to discuss public policies implemented and focused on indigenous school education both at the national, state and municipal levels, especially in the municipality of Dourados/MS, where the second largest indigenous population. This is an excerpt from our Doctoral Thesis, defended in 2019 by the Graduate Program in Education at the Federal University of Grande Dourados, whose methodology was based on Cultural studies and educational ethnography. The study points out that even with the advances regarding national public policies there is still a great challenge in the municipal field, as its policies do not contemplate the needs and specificities of school education of the indigenous people of Dourados / MS. We hope that such a discussion will contribute to the rethinking of local public policies in order to fulfill and expand the legal guarantees already achieved nationally by the indigenous people.
\end{abstract}

KEYWORDS: Public Policies. Legal provisions. Indigenous School Education.

\title{
Resumen
}

Las políticas educativas públicas dirigidas a la gente indígena han revelado avances significativos desde la Constitución Federal brasileña de 1988, que cuenta con artículos específicos que garantizan el respeto de la educación escolar indígena por la lengua materna y el modo de aprendizaje propio de las comunidades. En esta perspectiva, este artículo busca discutir las políticas públicas implementadas y enfocadas en la educación escolar indígena tanto a nivel nacional, estatal y municipal, especialmente en el municipio de Dourados / MS, donde el segundo mayor población indígena. Este es un extracto de nuestra Tesis Doctoral, defendida en 2019 por el Programa de Posgrado en Educación de la Universidad Federal de Grande Dourados, cuya metodología se basó en los estudios culturales y la etnografía educativa. El estudio señala que a pesar de los avances en materia de políticas públicas nacionales aún existe un gran desafío en el ámbito municipal, ya que sus políticas no contemplan las necesidades y especificidades de la educación escolar de los indígenas de Dourados / MS. Esperamos que tal discusión contribuya a repensar las políticas públicas locales para cumplir y ampliar las garantías legales ya logradas a nivel nacional por los pueblos indígenas.

PALABRAS CLAVE: Políticas Públicas. Provisiones legales. Educación escolar indígena.

\section{INTRODUÇÃO}

A escolarização dos indígenas surgiu, no Brasil, com a chegada dos colonizadores espanhóis, e posteriormente com a chegada dos portugueses. Dentre os exploradores das riquezas materiais dos indígenas estavam os religiosos, cujo interesse 
era o de catequizar aqueles que eram considerados sem religião e sem nenhuma crença. Pautados por uma educação integracionista, assimilacionista e homogeneizadora, os Jesuítas dedicaram-se ao ensino das letras, contudo com o objetivo maior de manter os indígenas subjugados às suas orientações e suas ordens.

Mediante diferentes explorações, o Brasil foi acusado de negligência e de falta de cuidado para com os indigenas, pelos governantes estrangeiros. Para reparar esta situação, foi criado o Serviço de Proteção ao Índio (SPI), em 1910, que além de proteger os territórios habitados pelos indígenas, responsabilizou-se pela sua educação. Com métodos herdados pelos jesuítas o ensino era ministrado em língua portuguesa inclusive com a proibição do uso da Língua Materna.

No dia 5 de dezembro de 1967, com a extinção da SPI, foi criada (SPI) a Fundação Nacional do Índio (FUNAI). Das demandas existentes, a Fundação assumiu a educação escolar indígena. Contudo, com pouca habilidade para este trabalho educacional específico, a FUNAI delegou a educação escolar indígena, por meio de parceria, aos missionários do Summer Institute of Linguistics (SIL), uma Instituição Missionária Evangélica com sede nos Estados Unidos, cujo objetivo principal, no Brasil, era a tradução da Bíblia em diversas línguas indígenas e a evangelização dos povos da floresta.

Dentre as ações realizadas, com o aval da FUNAI, o SIL implantou, nos anos 70, o ensino bilíngue, iniciando pelas comunidades indígenas Kaingang, no Sul do Brasil; Terena, no Mato Grosso do Sul e Karajá, no Tocantins. Espalhando-se posteriormente por outras etnias, como por exemplo: os Guarani e os Kaiowá, também no Mato Grosso do Sul.

Embora o crescimento das escolas entre as comunidades indígenas fosse notório, pouco se percebeu quanto às mudanças no sistema educacional oferecidas para estas populações. Pelo contrário, o ensino continuou formatado nos parâmetros utilizados pelas e nas escolas para os alunos não indígenas.

Melià (1979), ao considerar o contexto da época, salienta que as escolas indígenas cumpriam, exclusivamente, um programa teórico, sem a possibilidade de práticas que dialogassem com o contexto onde as escolas estavam inseridas. Para o antropólogo espanhol, tanto os horários, como o calendário escolar eram fixos, determinados pelas Secretarias de Educação Municipais as datas denunciavam o desrespeito pelas atividades realizadas pelos indígenas, como, por exemplo, o tempo de caça, de plantio e da colheita, o que além do comércio garantia a sobrevivência das famílias.

Do mesmo modo, Melià (1979) faz menção ao material utilizado nas escolas indígenas, observando serem os mesmos utilizados nas escolas encontradas no interior do Brasil. Composto por cadernos, lápis, borracha, giz e mapas, ao kit de material somavam-se às cartilhas, livros de leituras e livros didáticos de iniciação à matemática, ciências e estudos sociais.

Seus estudos, realizados nos anos 70, apontaram que não havia nenhuma preparação pedagógica que atendesse às necessidades e demandas específicas dos alunos indígenas. A escola era uma instituição descontextualizada, sem significado e incapaz de despertar o interesse dos sujeitos para quem ela fora criada.

Embora o Brasil contasse com seis Constituições Federativas, nenhuma delas sinalizou qualquer referência de como a educação escolar para os indigenas deveria ser organizada ou balizada. Somente nos anos de 1980, particularmente em 1988, com o advento da Constituição Federal Brasileira, os indígenas receberam alguma atenção quanto a sua educação escolar, pois o documento garantiu a eles uma educação com 
respeito à língua materna e ao seu modo próprio de aprendizagem. Nessa perspectiva, este artigo busca discutir as políticas públicas implementadas e voltadas para a educação escolar indígena tanto ao que tange o nível nacional como o nível municipal, em especial no município de Dourados/MS, local onde encontra-se a segunda maior população indígena.

Trata-se de um recorte da nossa Tese de Doutoramento, defendida no ano 2019 pelo Programa de Pós-Graduação em Educação da Universidade Federal da Grande Dourados, cuja metodologia pautou-se nos estudos Culturais e na etnografia educacional. Os resultados do estudo apontam que mesmo com os avanços acerca das políticas públicas nacionais, ainda há um grande desafio no campo municipal, pois suas políticas não contemplam as necessidades e as especificidades da educação escolar dos indígenas de Dourados/MS. Esperamos que tal discussão contribua para que as políticas públicas locais sejam repensadas a fim de cumprir e ampliar as garantias legais já conquistadas nacionalmente pelos indígenas.

\section{Primeiros dispositivos legais a favor da educação escolar indígena}

A história constitucional do Brasil sempre esteve atravessada pelos interesses coloniais, cujo objetivo era atender as pessoas mais abastardas da sociedade. O primeiro documento constitucional brasileiro outorgado foi a Constituição do Império do Brasil, em 1824. Embora já houvesse uma relação muito estreita entre os colonizadores e os indígenas, ainda que exploratória e baseada em conflitos e tensões, a Constituição de 1824 nada previu acerca dos indígenas. Pelo contrário, o seu interesse maior era o de atender as exigências de D. Pedro I, em manter o controle político e executivo por meio do veto, o que significava evitar a oposição de quaisquer outras constituintes.

A Lei, promulgada em 12 de agosto de 1834, após dez anos da primeira Constituição Brasileira, refere-se aos indígenas como "súditos cristãos e trabalhadores", (LEIVAS, RIOS e SCHÄFER, 2014, p. 374). Ideia que reforça o preconceito e a subalternidade existentes dos governantes para com os povos ameríndios.

Ainda que o Brasil tenha promulgado seis Constituições durante os anos de 1824 a 1988 (1824, 1834, 1937, 1946, 1967 e 1988), somente a Constituição Federal Brasileira de 1988, a última Constituição até o momento, considerou o indígena como cidadão brasileiro, com garantias ao seu modo de ser e de viver. O Artigo $5^{\circ}$ da referida Constituição destaca os direitos e os deveres individuais e coletivos do cidadão: "Todos são iguais perante a lei, sem distinção de qualquer natureza [...]". Os parágrafos que seguem ressaltam as seguridades, as garantias e os direitos do cidadão em solo brasileiro, além de seus deveres sob os regimes do País.

Quanto ao âmbito educacional, o Art. 205 garante que a educação é um direito de todos e dever do estado e deve ter a parceria da família, com vistas ao desenvolvimento e ao preparo para o trabalho de cada educando. O Art. 206, nos incisos I, II, III, IV, V, VI e VII, discorre sobre princípios para o ensino escolar, garantindo a igualdade de condições e a permanência do aluno na escola.

O Art. 210, parágrafo $2^{\circ}$, faz a primeira menção direta às populações indígenas. Define que o ensino fundamental regular deve ser ministrado em língua portuguesa, porém assegura a utilização da língua materna na escola e o respeito ao processo de ensino e aprendizagem dos indígenas. Diz o parágrafo: "O ensino fundamental regular será ministrado em língua portuguesa assegurada às comunidades indígenas também a 
utilização de suas línguas maternas e processos próprios de aprendizagem" (BRASIL, 2001).

Com base na Constituição Federal Brasileira de 1988, oito anos depois, a Lei de Diretrizes e Bases (LDB), número 9.394, de 1996, inclui dentre os artigos existentes, alguns outros que contemplam o respeito e o reconhecimento dos indígenas na construção do Brasil. Estabelece o Art. 26, parágrafo 4": "O ensino da História do Brasil levará em conta as contribuições das diferentes culturas e etnias para a formação do povo brasileiro, especialmente das matrizes indígenas, africana e europeia" (BRASIL, 1996).

Além deste, o Art. 78 assegura que o Sistema de Ensino da União e a colaboração das agências federais de fomento à cultura e de assistência aos índios "desenvolverá programas integrados de ensino e pesquisas, para oferta de Educação escolar bilíngue e intercultural aos povos indígenas" (BRASIL, 1996). Dentre os objetivos, assegurados no Art. 78 estão:

\begin{abstract}
I. Proporcionar aos índios, suas comunidades e povos, a recuperação de suas memórias históricas; a reafirmação de suas identidades étnicas; a valorização de suas línguas e ciências;

II. Garantir aos índios, suas comunidades e povos, o acesso às informações, conhecimentos técnicos e científicos da sociedade nacional e demais sociedades indígenas e não-índias (BRASIL, 1996).
\end{abstract}

Firmados nestes dispositivos legais, os indígenas intensificaram a sua luta quanto à educação e, a partir disso organizaram novos movimentos que resultaram em "mudança coerente" no âmbito educacional (MELIÀ, 1979). Ainda que a Constituição Federal Brasileira de 1988 e a LDB constituam-se em marco importante para a educação escolar indígena, ainda não foram suficientes para, de fato, suprir as demandas necessárias destas comunidades. Desta forma, em 1998, foi criado o Referencial Curricular Nacional para as Escolas Indígenas (RCNEI).

O documento aprofunda as exigências já estabelecidas pelos dois dispositivos supracitados e acrescenta objetivos que atendam os anseios, interesses e as necessidades da educação escolar indígena, inclusive quanto à formação de profissionais para assumirem tarefas que possam viabilizar e atender aos interesses da comunidade. A proposta do RCNEI pauta-se na perspectiva de que cada escola indígena "construa o seu próprio referencial de análise e avaliação do que nela está sendo feito e, ao mesmo tempo, elabore um planejamento adequado para o que nela se quer realizar" (BRASIL, 1998).

Compreendemos, a partir da proposta do RCNEI, que além de atender os objetivos educacionais da escola, ele elenca objetivos administrativos, pois é imprescindível um planejamento a fim de que sejam pensadas e avaliadas as ações estabelecidas pela comunidade escolar.

A Resolução de $n^{\circ}$ 3, de 10 de novembro de 1999, debruça-se na organização e gestão da escola nas aldeias indígenas. Visa o reconhecimento e o respeito pela língua, cultura e pelo aprendizado próprio do povo; a capacitação e a permanência do professor nativo nas escolas localizadas nas aldeias; a produção de material didático baseado no contexto da aldeia, com o currículo próprio que atendam às necessidades peculiares de cada povo.

Quanto a formação dos professores, o Art. 6, garante que: “A formação dos 
professores das escolas indígenas será específica, orientar-se-á pelas Diretrizes Curriculares Nacionais e será desenvolvida no âmbito das instituições formadoras de professores". Neste contexto, embora reconheçamos, por uma vertente, os avanços da educação escolar indígena, a partir dos dispositivos legais até aqui citados. Por outra vertente verificamos que há, ainda, uma fragilidade no sistema, pois as instruções para o professor indígena continuam com uma proposta firmada no modelo universal, e, por conseguinte, baseado na perspectiva integracionista (SOUZA, 2019).

Nesse caso, a partir dos estudos de Candau (2009), compreendemos que a formação dos professores indígenas precisa ter base na interculturalidade, com a possibilidade do reconhecimento e da valorização dos diversos sistemas culturais. Na perspectiva de uma formação multicultural ocorrem os diálogos e a partilha entre o conhecimento tradicional e o moderno, entre a cultura oral e a escrita. Por este caminho, embora acreditamos que os indígenas não estejam proibidos de terem suas formações em instituições diversas, sejam elas públicas ou privadas, devemos problematizar se estas instituições atendem, pelo menos minimamente as diretrizes dos documentos legais brasileiros.

\section{Plano Nacional de Educação e as novas Resoluções}

Pautado na Constituição Federal Brasileira de 1988, e em outros dispositivos legais, o Plano Nacional de Educação (PNE), de 09 de janeiro de 2001, intensifica, aprofunda e esclarece algumas proposições acerca da educação escolar indígena, das quais destacamos duas:

1. A Constituição Federal assegura às comunidades indígenas a utilização de suas línguas maternas e processos próprios de aprendizagem.

2. A educação bilíngue, adequada às peculiaridades culturais dos diferentes grupos, é melhor atendida através de professores índios. É preciso reconhecer que a formação inicial e continuada dos próprios índios, enquanto professores de suas comunidades devem ocorrer em serviço e concomitantemente à sua própria escolarização. A formação que se contempla deve capacitar os professores para a elaboração de currículos e programas específicos para as escolas indígenas; o ensino bilíngue, no que se refere à metodologia e ensino de segundas línguas e ao estabelecimento e uso de um sistema ortográfico das línguas maternas; a condução de pesquisas de caráter antropológico visando à sistematização e incorporação dos conhecimentos e saberes tradicionais das sociedades indígenas e à elaboração de materiais didático-pedagógicos, bilíngues ou não, para uso nas escolas instaladas em suas comunidades (BRASIL, 2001).

O documento propõe que o ensino bilíngue, ao que refere-se a culturas de diferentes grupos, deve ser atendido por professores indígenas e a formação destes professores devem contemplar as especificidades dos currículos, dos programas e das necessidades das escolas. Além disso, deve incorporar os saberes tradicionais da comunidade, a fim de que o material didático usado nas escolas reflita a forma de pensar e de ser do povo.

A Resolução $\mathrm{n}^{\circ}$ 4, de 13 de junho de 2010, no Art. 38, § I ao VI, volta-se para as estruturas sociais, as práticas socioculturais e religiosas; o respeito ao processo próprio de aprendizagem e a produção do conhecimento; a observação das atividades econômicas, a flexibilidade do calendário escolar; a estrutura física das escolas e a produção de material didático que atendam às necessidades socioculturais e linguísticas 
das diferentes comunidades indígenas.
I. Suas estruturas sociais;
II. Suas práticas socioculturais e religiosas; III. Suas formas de produção de conhecimento, processos próprios e métodos
de ensino-aprendizagem;
IV. Suas atividades econômicas;
V. Edificação de escolas que atendam aos interesses das comunidades indígenas;
VI. Uso de materiais didático-pedagógicos produzidos de acordo com o contexto sociocultural de cada povo indígena (BRASIL, 2010).

Como complemento a Resolução supracitada, no dia 22 de junho de 2012, a Câmara de Educação Básica do Conselho Nacional de Educação editou a Resolução ${ }^{\circ}{ }^{\circ}$ 5, e nela, dentre outras providências, estabelece que a formação da carreira docente deva ter base no magistério próprio para o indígena. Tal Resolução responde-nos, pelo menos, parcialmente os questionamentos feitos anteriormente nos ditames da Resolução $n^{\circ} 3$ de 1999, quanto à formação dos professores, pois supõe que de um documento para o outro houve uma análise, entretanto, uma mudança de perspectiva.

Diferentemente do Plano Nacional de Educação de 2001, e dos demais documentos citados posteriormente, o Plano Nacional de Educação de 2014, com vigência por 10 anos, destaca aspectos pontuais à educação escolar indígena na educação básica. Na meta 1, ao tratar da universalização da pré-escola - 4 e 5 anos - e da ampliação da oferta nas creches, tem-se como estratégia:

Estratégia 1.10 - fomentar o atendimento da educação infantil nas respectivas
comunidades indígenas, levando em consideração a distribuição territorial da
oferta, limitando a nucleação de escolas e o deslocamento de crianças, de
forma a atender às especificidades das comunidades, garantido consulta
prévia e informada (BRASIL/PNE, 2014).

Na meta 2, a universalização do ensino fundamental de 9 (nove) anos, o PNE 2014 definem duas estratégias:

Estratégia 2.6 - desenvolver tecnologias pedagógicas que combinem, de maneira articulada, a organização do tempo e das atividades didáticas entre a escola e o ambiente comunitário, considerando as especificidades da educação especial, das escolas do campo e das comunidades indígenas e quilombolas;

Estratégia 2.10 - estimular a oferta do ensino fundamental, em especial dos anos iniciais, para as populações do campo, indígenas e quilombolas, nas próprias comunidades (BRASIL/PNE, 2014).

A estratégia 2.6 acrescenta o uso de tecnologias pedagógicas, articulando-as com o tempo e demais atividades propostas, bem como com os diálogos nos ambientes comunitários. Inseri na sua estratégia o público da educação especial, as escolas do campo e os quilombolas, contudo em nenhum momento menciona os processos próprios de aprendizagem dos povos indígenas.

Quanto à universalização do atendimento escolar para a população de 15 a 17 anos de idade, o PNE 2014 presenta como estratégia 3.7 " [...] fomento de matrículas gratuitas de ensino médio integrado à educação profissional, em observância às peculiaridades das comunidades indígenas [...]". Na perspectiva da educação especial, as estratégias contemplam pessoas de 04 a 17 anos de idade que tenham deficiência, transtornos 
globais do desenvolvimento e altas habilidades ou superdotação. A meta 4.3 propõe: "[...] implantar, ao longo deste PNE, salas de recursos multifuncionais [...]", e, além disso deve-se "[...] fomentar a formação continuada de professores e professoras para o atendimento educacional especializado nas escolas urbanas, do campo, indígenas e de comunidades quilombolas $[. .$.$] ".$

O PNE de 2014, determina que as crianças sejam alfabetizadas, no máximo, até o final do terceiro ano do ensino fundamental, destacando na estratégia 5.5, o apoio "[...] a alfabetização de crianças do campo, indígenas, quilombolas e de populações itinerantes [...]", levando em consideração "[...] a produção de materiais didáticos específicos, e desenvolver instrumentos de acompanhamento que considerem o uso da língua materna pelas comunidades indígenas e a identidade cultural das comunidades quilombolas $[\ldots]$ ”.

A meta 6, do mesmo documento, trata da educação em tempo integral, quanto aos indígenas, a estratégia 6.7 propõe "[...] atender às escolas do campo e de comunidades indígenas e quilombolas na oferta de educação em tempo integral, com base em consulta prévia e informada, considerando-se as peculiaridades locais [...]". Além disso, a estratégia 7.25 tem como pressuposto "[...] garantir nos currículos escolares conteúdos sobre a história e as culturas afro-brasileira e indígena [...]" e a estratégia 7.26 toma como referência:

\footnotetext{
Estratégia 7.26 - consolidar a educação escolar no campo de populações tradicionais, de populações itinerantes e de comunidades indígenas e quilombolas, respeitando a articulação entre os ambientes escolares e comunitários e garantindo: o desenvolvimento sustentável e preservação da identidade cultural; a participação da comunidade na definição do modelo de organização pedagógica e de gestão das instituições, consideradas as práticas socioculturais e as formas particulares de organização do tempo; a oferta bilíngue na educação infantil e nos anos iniciais do ensino fundamental, em língua materna das comunidades indígenas e em língua portuguesa; a reestruturação e a aquisição de equipamentos; a oferta de programa para a formação inicial e continuada de profissionais da educação; e o atendimento em educação especial.
}

Ao direcionar a oferta da Educação de Jovens e Adultos (EJA) nos ensinos fundamental e médio, a meta 10, estratégia 10.3 tem como foco "[...] fomentar a integração da educação de jovens e adultos com a educação profissional, em cursos planejados [...]", isto com respeito as características do público da EJA, considerando "[...] as especificidades das populações itinerantes e do campo e das comunidades indígenas e quilombolas, inclusive na modalidade de educação a distância [...]".

A estratégia 9, da meta 11, tem como objetivo "[...] expandir o atendimento do ensino médio gratuito integrado à formação profissional para as populações do campo e para as comunidades indígenas e quilombolas, de acordo com os seus interesses e necessidades [...]". O PNE de 2014 continua a abordagem da formação profissional na estratégia 15.5 ao "[...] implementar programas específicos para formação de profissionais da educação para as escolas do campo e de comunidades indígenas e quilombolas e para a educação especial $[\ldots]$ "..

Ao tratar de provimentos de cargos para as escolas com a proposta da educação diferenciada, a meta 18 do PNE de 2014, na estratégia 18.6 aponta que ao ser estabelecido o plano de carreira para a educação básica e superior pública deve-se “[...] considerar as especificidades socioculturais das escolas do campo e das comunidades indígenas e quilombolas no provimento de cargos efetivos para essas escolas [...]". 
Mediante as referências apresentadas no Plano Nacional de Educação 2014, com vigência em 2024, percebemos que juntamente com a população indígena, o documento destaca a população do campo e os quilombolas, enquanto o PNE 2001 referia-se separadamente cada uma destas populações. Dentre as metas que ora reafirma, ora amplia os documentos anteriores destacamos o incentivo ao ensino profissionalizante especificamente para os indígenas. De certa forma, esta estratégia estimula que os jovens indígenas busquem possibilidades além das suas aldeias, profissionalizando-se e aspirando novos horizontes.

O Plano Nacional de Educação de 2014 apresenta-se como mais um novo avanço para a educação escolar indígena, que junto com a implantações dos Territórios Etnoeducacionais podem traçar novos e desafiadores caminhos para a educação deste povo tão específico.

\section{Dispositivos legais para a educação escolar indígena no Estado do Mato Grosso do Sul}

Quanto aos dispositivos estaduais, o Estado do Mato Grosso do Sul, a partir da Deliberação CEE/MS N ${ }^{\circ} 10.647$, de 28 de abril de 2015 normatiza a oferta da educação escolar indígena em nível estadual. $\mathrm{O}$ documento, com base nas diretrizes nacionais, propõe que a educação escolar indígena deve ser pautada pela diferença, pelo bilinguismo/multilinguismo e pela interculturalidade.

$\mathrm{O}$ Art. $3^{\circ}$, parágrafo VI, dispõe que a organização da escola indígena deve ter a "[...] colaboração e a atuação de especialistas em conhecimentos tradicionais [...]". Dentre estes, o documento especifica: "[...] os tocadores de instrumentos musicais, contadores de narrativas míticas, artesãos, pajés ou xamãs, rezadores, raizeiros, parteiras [...]”. E, além disso “[...] 'os mais velhos', organizadores de rituais, conselheiros e outras funções próprias e necessárias ao bem viver dos povos indígenas". Ao destacar o Artigo supracitado observamos a especificação do documento, assim como $o$ reconhecimento e o respeito pelos conhecimentos e pelos saberes tradicionais dos indígenas, tanto ao que refere-se a perspectiva religiosa, quanto a perspectiva administrativa das comunidades.

Nessa mesma direção, de reconhecimento a diferença, o documento trata, dentre outros assuntos, da produção e do uso de material didático na escola indígena. O Art. $11^{\circ}$ garante que o material didático deve ser produzido, em regime de colaboração, em língua materna e em língua portuguesa, a fim de atender a necessidade comunicativa de cada aluno. O Art. $12^{\circ}$ complementa que, as escolas indígenas devem receber apoio técnico e financeiro para que tenham condições de produzir seus materiais didáticos.

O Capítulo $\mathrm{V}$ do documento, trata da formação dos profissionais da educação escolar indígena, destacando que a formação inicial dos professores indígenas deve ser realizada em cursos específicos de licenciaturas e pedagogias interculturais, ou outros cursos destinados ao magistério indígenas, de modo a atender as demandas e singularidades das comunidades indígenas. Assim, também, deve ser a formação continuada, de forma "[...] específica articulada à sua formação inicial e à realidade da escola indígena [...]" (Art. 48, § $6^{\circ}$ ).

Cabe destacar que, a Deliberação do Conselho Estadual de Educação do Estado do Mato Grosso do Sul, em seus respectivos Artigos, Parágrafos e incisos busca documentalmente considerar a pluralidade étnica existente no Estado sul-matogrossense, bem como a necessidade da educação diferenciada, na perspectiva multicultural, já garantida nos dispositivos nacionais. 


\section{Os desafios de dispositivos legais para a educação escolar indígena no município de Dourados/MS}

O município de Dourados está localizado na região Sul do Estado do Mato Grosso do Sul, há 229,3 quilômetros da capital do Estado, Campo Grande. Segundo os dados do Instituto Brasileiro de Geografia e Estatística (IBGE), o número de população estimada em Dourados, no ano de 2019 é de 222.949 pessoas. Desta população, cerca de 12 mil são indígenas.

$\mathrm{Na}$ cidade de Dourados encontra-se a Reserva Indígena Francisco Horta Barbosa, considerada a maior Reserva Indígena do Estado sul-mato-grossense. Distante cerca de dois quilômetros do centro urbano, a Reserva está localizada as margens da Rodovia MS 156, que liga as cidades de Dourados a Itaporã.

\section{Imagem 1 - Demonstrativo da Reserva Indígena Francisco Horta Barbosa em Dourados/MS}

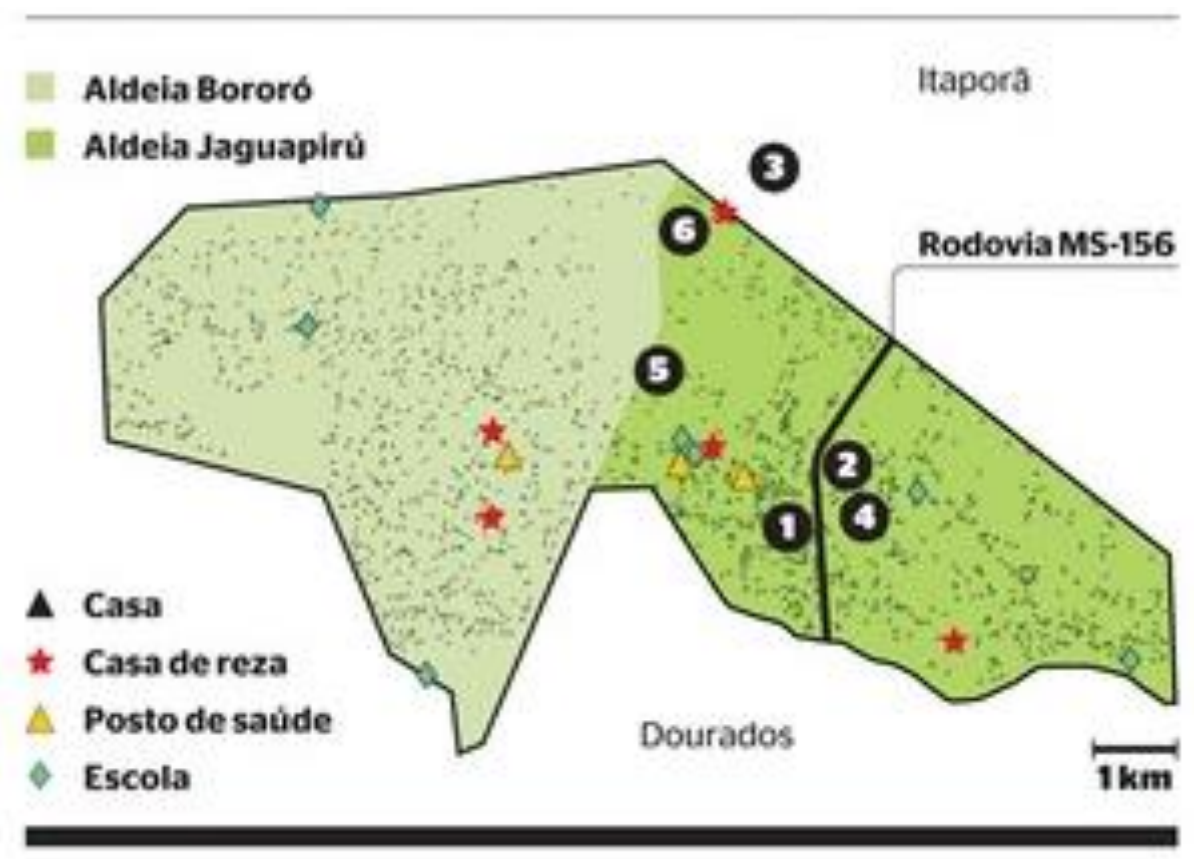

Fonte: (SORDI, 2018, p. 50)

No interior da Reserva encontram-se duas aldeias: a Aldeia Jaguapiru e a Aldeia Bororo, cujos moradores pertencem as etnias Kaiowá, Guarani Ñandeva e Terena. Sendo em maior número os indígenas Kaiowá, seguido dos Guarani e em menor número os Terenas.

Pertencentes ao tronco linguístico Tupi, os Kaiowá e os Guarani Ñandeva são falantes da língua Guarani. E, embora os dois grupos assegurem que suas línguas sejam diferentes, elas são geneticamente aparentadas, devido os aspectos morfológicos fonológicos (RODRIGUES, 2011).

Quanto aos Terenas, a sua língua pertence ao troco Aruak diferenciando completamente da língua dos Kaiowá e dos Guarani. Em meio as diferenças linguísticas destes grupos indígenas está a língua portuguesa, que de certa forma influencia cotidianamente a vida social e educacional da comunidade, devido ao contexto híbrido em que vivem. 
Os moradores da Reserva Indígena Francisco Horta Barbosa contam com seis escolas indígenas municipais localizadas nas duas aldeias supracitadas, uma escola municipal sob a responsabilidade da Missão Caiouá ${ }^{2}$, localizada em um espaço próximo a aldeia Jaguapiru, com atendimento de $99 \%$ a alunos indígenas e uma escola estadual, situada na aldeia Jaguapiru, onde atende alunos indígenas do ensino médio.

Mediante as diversidades culturais e linguísticas dos indígenas Kaiowá, Guarani e Terena, o município de Dourados encontra-se frente a muitos desafios e um deles e o desafio educacional, pois ainda que os dispositivos legais apresentados anteriormente garantam a educação diferenciada para os indígenas, é necessário que o município busque atender as necessidades e as especificidades desta população.

Nesta perspectiva, ao analisarmos os documentos elaborados pelo município de Dourados/MS, verificamos que o Plano Municipal de Educação (2015-2025), do município (PME/MS), tem uma abordagem limitada, ao que tange a educação escolar indígena. O Plano Municipal de Educação não apresenta nenhuma especificidade quanto ao atendimento às escolas indígenas, pelo contrário, ele é uma cópia do Plano Nacional de Educação quanto as suas Metas e Estratégias, inclusive com o mesmo formato e organização do documento nacional.

O diferencial do documento está, apenas no destaque aos nomes de todas as escolas do município em um quadro - onde estão incluídos os nomes das escolas indígenas; o número de alunos matriculados no ano de 2014, sendo o número total de alunos 3.563 indígenas contando os matriculados na educação infantil e nos anos iniciais do ensino fundamental; e os indicadores dos anos de 2014, usando como base o Brasil, o Estado do Mato Grosso do Sul e do Município de Dourados, sem nenhuma menção especifica aos indígenas.

Vale lembrar que, assim como o PNE, as estratégias contemplam juntamente as comunidades indígenas, a população do campo e os quilombolas. Se por um lado o documento distingue a educação escolar indígena da educação do campo - o que por muito tempo foram colocadas como iguais equivocadamente. Por outro lado, consideramos que o lugar que os indígenas ocupam no documento, ainda é muito pequeno em comparação ao número da população indígena que vive nas duas Aldeias de Dourados/MS, as diferentes etnias que moram no mesmo espaço geográfico, e, em especial o número de escolas localizadas na Reserva Indígena Francisco Horta Barbosa.

Mediante o quadro apresentado ao que concerne o documento municipal de educação, consideramos que há um grande desafio no que tange a educação escolar indígena no município de Dourados/MS. Pois, é preciso urgentemente em repensar as estratégias e as metas específicas acerca da educação escolar indígena. É preciso discutir políticas linguísticas que supram as necessidades das diferentes etnias, já que estas pertencem a troncos linguísticos distintos e ainda recebem influências cotidianas da língua portuguesa.

É necessário, ainda estabelecer diretrizes para o atendimento educacional dos indígenas Kaiowá, Guarani e Terena a partir da perspectiva da educação diferenciada e multicultural.

\section{CONSIDERAÇÕES FINAIS}

\footnotetext{
${ }^{2}$ Missão Evangélica, sob a direção da Igreja Presbiteriana. Suas atividades escolares iniciaram em 1931 (SOUZA, 2019).
} 
A educação escolar indígena passou por diferentes processos desde a chegada dos Jesuítas no Brasil. Pautada pela educação catequista os religiosos ensinaram os indígenas a ler, escrever e contar, para assim alcançar os seus objetivos de subalternidade. Não foram poucas as denúncias de países estrangeiros sobre a acusação de que o Brasil estava matando os seus indígenas, extinguindo-os aos poucos.

Graças a estas denúncias o governo brasileiro tomou providências, criando órgãos como o Serviço de Proteção ao Î́ndio e depois a Fundação Nacional do Índio. Embora estas instituições tivessem seus papéis em relação aos indígenas, não conseguiram oferecer aos indígenas uma educação que atendesse as suas demandas e necessidades. Foram os próprios indígenas que, por meio de movimentos em diferentes pontos do país conseguiram a atenção do governo para inserir suas causas em documentos legais, em especial no capítulo educação.

Primeiramente eles apareceram na Constituição Federal Brasileira de 1988, seguindo pela Lei de Diretrizes e Bases e tempo depois ganharam espaço exclusivo no Referencial Curricular Nacional para as escolas indígenas. Tais documentos desdobraram-se em documentos estaduais e municipais que garantem a educação escolar indígena numa perspectiva diferenciada, com respeito a sua cultura, a sua língua e o seu modo de ser, de viver e de aprender.

O Estado do Mato Grosso do Sul, segundo maior em número de população indígena do Brasil, traz em seus dispositivos legais a preocupação com a escola indígena, com a formação do professor indígena, com a produção de material didático pelos indígenas e com o diálogo com a comunidade e liderança administrativa e religiosa.

No que tange aos dispositivos municipais, os dispositivos legais encontrados na cidade de Dourados/MS está muito aquém de comtemplar as especificidades da grande população que vive na Reserva Francisco Horta Barbosa e dos alunos matriculados nas escolas ali localizadas. Neste sentido, compreendemos que o município de Dourados/MS tem pela frente um grande desafio, visto a multiplicidade cultural e linguística que encontra-se nas seis escolas espalhadas pelas aldeias Jaguapiru e Bororo.

\section{REFERÊNCIAS}

BRASIL. Plano Nacional de Educação. Lei $n^{o} 13.005 / 2014$. Câmara dos Deputados. Brasília,2014.

Resolução $N^{o}$ 5, de 22 de junho de 2012. Ministério da Educação Conselho Nacional de Educação. Câmara de Educação Básica. Brasília:2012.

Resolução $N^{o}$ 4, de 13 de julho de 2010.Ministério da Educação Conselho Nacional de Educação. Câmara de Educação Básica. Brasília:2010.

Constituição Federal Brasileira de 1988. Constituição Da República Federativa do Brasil. $17^{\circ}$ ed. Brasília: Centro de Documentação e Informação - Coordenação de Publicações,2001. 
Plano Nacional de Educação. Lei $N^{o}$ 10.172, de 9 de janeiro de 2001. Câmara dos Deputados. Brasília,2001.

Resolução CEB $N^{o}$ 3, de 10 de novembro 1999. Ministério da Educação Conselho Nacional de Educação. Câmara de Educação Básica. Brasília:1999.

Referencial Curricular Nacional para as Escolas Indígenas. Ministério da Educação e do desporto - Secretaria de Educação Fundamental. Brasília: MEC,1998.

Lei ${ }^{\circ}$ 9.394, de 20 de dezembro de 1996. Estabelece a Lei de Diretrizes $e$ Bases da Educação Nacional. Diário Oficial da República Federativa do Brasil, DF, n. 248, 23 de dez.1996.

. Lei $n^{o} 16$ de 12 de agosto de 1834. Presidência da República. Brasil,1834.

Constituição do Império do Brasil. Império do Brasil. Brasil, 1824.

CANDAU, Vera Maria. Educação Intercultural na América Latina: Tensões atuais. Trabalho apresentado no Congresso Iberoamericano de História da Educação na América Latina (CIHELA), realizado na UERJ, 2009.

CAMPO GRANDE. Deliberação CEE/MS n $n^{\circ}$ 10.647, de 28 de abril de 2015. Conselho Estadual de Educação/MS. Campo Grande/MS, 2015.

DOURADOS. Plano Municipal de Educação 2015-2025. Secretaria Municipal de Educação de Dourados/MS. Dourados/MS: SEMED, 2015.

LEIVAS, Paulo Gilberto Cogo; RIOS, Roger Raupp; SCHÄFER, Gilberto. Educação Escolar Indígena no Direito brasileiro: Do paradigma integracionista ao paradigma do direito a uma educação diferenciada. Revista da AJURIS. v. 41, n. 136, Dezembro 2014.

MELIÀ, Bartolomeu. Educação indígena e alfabetização. São Paulo: Edições Loyola, 1979.

RODRIGUES, Aryon Dall'Igna. Esboço de uma introdução ao estudo da língua Tupí. Revista Brasileira Linguística Antropológica. Volume 3, Número 1, Julho de 2011.p. 31-44.

SORDI, Adriana Rita. A constituição do sujeito indígena jovem Kaiowá e Terena: um estudo a partir da teoria da subjetividade. Tese (Doutorado em Psicologia). UCDB: 
Campo Grande, 2018. Programa de Pós-Graduação Mestrado e Doutorado em Psicologia. UCDB: Campo Grande, 2018.

SOUZA, Ilma Regina Castro Saramago de Souza. Práticas pedagógicas e diálogos interculturais no cotidiano da educação escolar indígena dos Guarani e Kaiowá em Dourados/MS.2019. 189 f. Tese (Doutorado em educação). Programa de Pós-Graduação da Universidade Federal da Grande Dourados Universidade Federal da Grande Dourados. Dourados/MS, 2019.

Colonização, descolonização e relações de poder: Diálogos com a educação escolar indígena. REA |Nº 4| julio de 2017 - Dosier 'Etnologia indígena', p. 36-44.

Recebido:10/03/2020

Aprovado: 09/05/2020 